\title{
Design and Realization of Online Teaching Platform Based on WebPlus in Medical University
}

\author{
Qinglian Yu1,a, Tao Qi ${ }^{2}$ \\ ${ }^{1}$ Modern Education Technology Center, Qiqihar Medical University, Qiqihar, China \\ ${ }^{2}$ Qiqihar No. 6 Middle School, Qiqihar, China
}

\begin{abstract}
Online teaching platform is a teaching method that advocates the guidance of teachers and focuses on students. The traditional teaching mode can't meet the education mode in the information age, the position and function of teaching platform and teaching resources in the teaching activities of teachers and students are becoming more and more obvious. Based on the management platform of the website group, this paper builds a online teaching platform conforming to the teaching characteristics of medical colleges, aiming at completing the intellectualization of the teaching platform and effectiveness of the design of teaching resources, stimulating students' enthusiasm for learning and improving teachers' teaching quality.

Keywords: Website group; teaching platform; teaching resources
\end{abstract}

\section{The introduction}

With the rapid development of computer and network technology, the application of online teaching are more and more common, the traditional single PPT courseware has been unable to meet the current form of teaching, education workers in colleges and universities must follow the time development pace, update teaching ideas, always be prepared to accept the new knowledge [1], online teaching platform arises at the historic moment. The online teaching platform is more and more popular among teachers and students because of its rich content, vivid image and strong interaction [2]. Medical colleges and universities teachers' computer level is limited, medical teaching experiments of video and image is more, based on the individual design of online teaching course sections of a single or design for more words, content rich and vivid enough, practicality is not strong, so that caused the cost a lot of manpower material resources to create the online teaching of course utilization rate is not high, resource sharing is difficult, not reached the reasonable use of resources, not convenient students' learning and teachers' teaching. According to the teaching characteristics of medical colleges and universities, this paper constructs the online teaching platform in line with the teaching rules of medical colleges and universities. The design of online teaching platform should reflect modern education theory, reflect advanced education thought [3-4], and also improve the teaching quality and students' learning skills [5]. Due to the fast update speed of computer technology and the high cost of education input, the research and development of network teaching platform requires a large amount of manpower, material resources and time [6], which should be saved as much as possible in the construction process. It is of great significance to establish a unified online teaching platform, and it is also of great importance to meet the teaching needs of teachers in medical colleges and the call for students to learn independently. Especially, it is particularly important in the context of education industry's continuous deepening of informatization construction.

\section{Technical framework of WebPlus}

WebPlus is mainly a platform tool for express delivery to build an information portal website. This platform tool can conveniently integrate structured and unstructured information data and various application systems, and can display the information of the website portal. The functions of online teaching platform are realized by the functional components of the application background, and the personalized online teaching platform is constructed by using the platform. This platform covers teachers' personal basic situation, teaching courses, key and difficult explanation, classroom exercises, homework after class, online answering, interaction between teachers and students and other rich teaching resources. Network teaching platform is not only a teaching platform, but also a platform for teacher-student communication [7].

\subsection{Simplified editing in background}

WebPlus offers a visual online article editing tool that is as easy to edit as Word. WebPlus editors can also insert, upload various document attachments, and even directly

a Corresponding author: yuqinglian@qmu.edu.cn 
insert media files. Edit the layout as shown below.

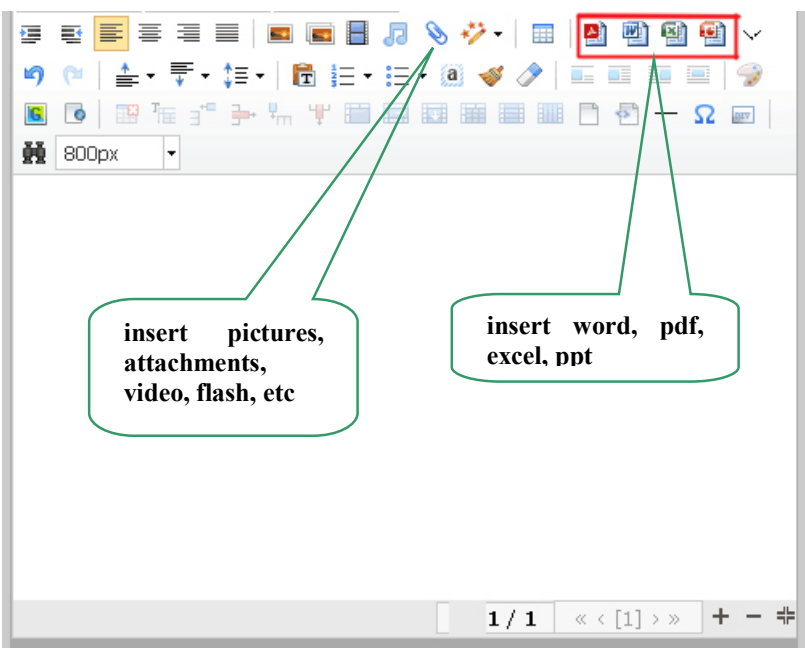

Figure 1. Visual background editing

\subsection{Quick release and revision}

WebPlus provides quick and easy ways to build websites, such as wizard and copy. All templates are simple Html files or fragments. Users can make them by themselves and have low requirements for professional skills. Html editing tools such as FrontPage, Dreamweaver and even Word can be used to complete them. There is no executable code in the template, and a rich and colorful display interface can be configured without writing the code, which not only ensures the system security but also reduces the difficulty of learning and making. Administrators can add as many templates to a website as they like, binding color styles, composition structures, and information content to each column within each template. The process of making and adjusting the new template does not affect the normal operation of the original configuration of the website. When the adjustment is satisfied and no mistake is made, the new template can be officially used to modify the whole website in an instant.

\section{Design personalized online teaching platform by application of WebPlus}

The purpose of developing online teaching platform is to meet the needs of teachers and students in the era of rapid information development, so that education teaching activities can achieve better results. On the one hand, it is more convenient for teachers to teach; on the other hand, the needs of students to learn independently can meet. In terms of functional design, the platform must take teaching as the first priority and insist on student-centered design. The main process of conventional teaching should be reflected in the online teaching platform, including the following aspects [8]: course design and release, resource download, online test, homework, performance query, teacher-student interaction, etc. In general, the function integration of the online learning platform is easy to design as a function module. According to the requirements of the platform, it mainly covers the function module before teaching, the module in specific teaching and the after-school guidance module after teaching, as shown in the figure below.

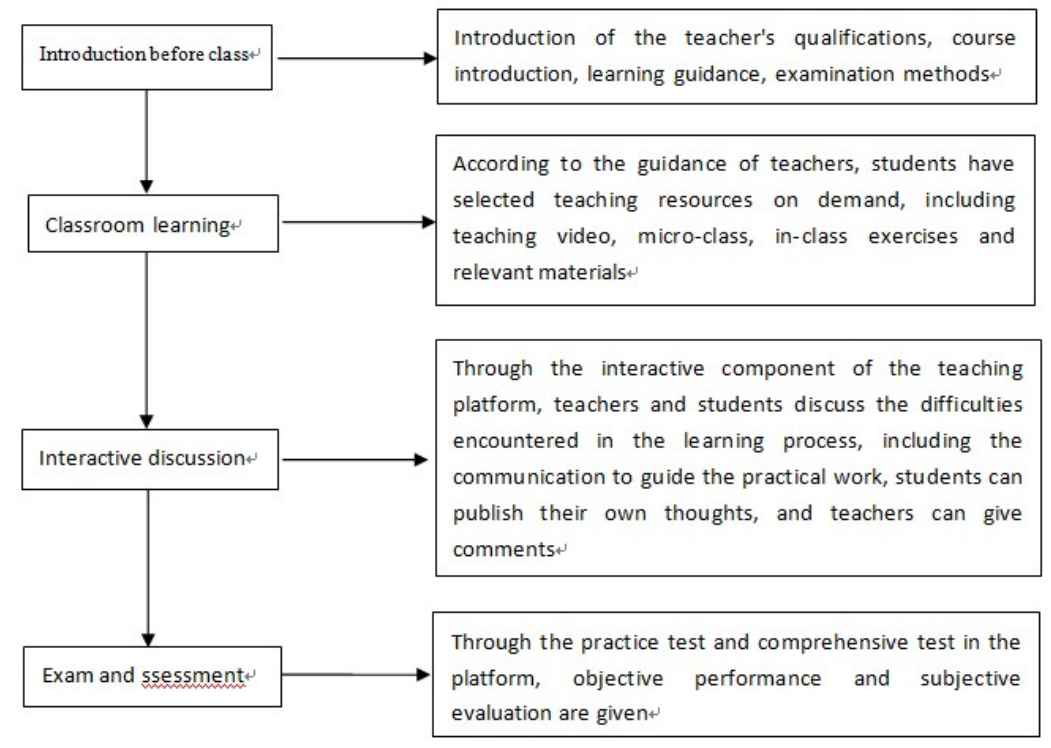

Figure 2. Basic modules of the teaching platform

\subsection{Function design before teaching}

The pre-teaching functional modules mainly include the personal introduction, course introduction, course design and release and other related management functions. This functional module is mainly about information display. Students have a preliminary understanding of the teachers through their personal education, scientific research achievements, professional titles and other aspects, which is convenient for students to choose courses. The teacher 
also carries out the content release work such as course design, specific chapter layout, course explanation and analysis, etc., and the students' pre-class and after-class review can also be operated through this platform.

\subsection{Function demonstration in teaching}

The online teaching function in the teaching platform is the main part of the whole platform. This paper wants to establish is a personalized and customized teaching platform in line with the teaching in medical colleges, the teaching courses on the platform are divided into theoretical teaching and experimental teaching. In the specific teaching process, it is divided into PPT course explanation, video demonstration, micro class demonstration of key and difficult knowledge, and individual analysis of teaching images. The whole platform involves a lot of contents in the teaching process, and it is not a single video that can explain a medical course clearly. Each course needs to be customized and refined gradually in the process of application.

PPT courseware added to the teaching platform requires large contrast between background color and font color, clear font size, convincing illustrations in courseware without copyright disputes, reasonable insertion of video format that can be normally played. As a new teaching method, micro class teaching uses information technology to make use of fragmented time in accordance with cognitive laws to learn certain knowledge points. The length of micro class is 5-8 minutes commonly, the longest should not exceed 10 minutes. Micro class is mainly to highlight the teaching of certain knowledge points in classroom teaching (such as key points, difficult points and doubtful points in teaching), which is a complete presentation of knowledge points. The difference between micro class and traditional video teaching lies in the length of time, but it also belongs to the category of video teaching. The processing of video here adopts the streaming server, which has high technical requirements for the system. The system must have an efficient server engine built in and apply multithread and multi-concurrent flow processing technology, which can meet the demand of multiple users to watch the teaching video at the same time. Video format needs to adopt current most advanced standards, and should be compatible with various current popular media formats, as far as possible to reduce the requirements of computer configuration, without additional software installation, convenient promotion and application.

The examination of teaching effect needs to be carried out through the test method. According to the teaching content and teaching requirements, the online test questions can be designed, and the question types can be selected, filled in, answered simply, and the case analysis, etc. Teachers can set questions in sections or in the whole course. Specific questions can be divided into different levels of difficulty. Students can master knowledge step by step. The objective questions are automatically graded by the system, while the subjective questions are reviewed and given online by the teacher, and the students' scores of this course are automatically synthesized and generated by the system.

\subsection{After-class counseling function}

The design of function module mainly reflected on the interactive capabilities, teachers can according to the requirement of the curriculum content arrangement of various practice teaching and plan, students can independently according to the requirements of teachers' practice study, within the prescribed period of time to upload to learn as a result, teachers timely according to the results of the student's study gives comments and grades, complete the teaching interaction.

Online Answering questions is also an interactive communication, students can interact with teachers via the Internet with the key points and difficulties of what they have learned. Teachers are required to respond to students' doubts in a timely and rapid manner, so as to improve students' interest and efficiency in learning, and at the same time, effectively improve the use efficiency of online teaching platforms and promote their healthy development.

\section{Conclusion}

In the field of modern education, education teaching mode has been changed in higher medical colleges and universities. The application of online teaching platform promotes and reform the existing teaching mode, enriches teaching methods and teaching approaches, provides students with personalized development space, improves teaching quality and promotes the development of the discipline. As a rapidly developing teaching form, network teaching platform has been increasingly valued in the current information-based education environment, so as to effectively promote the healthy and orderly development and management of education teaching functions.

\section{Acknowledgement}

This work was supported by guidance project of the science and technology bureau of Qiqihar, Heilongjiang Province under grant No.GYZD-2017010.

\section{References}

1. Mian Wang. Design and implementation of network teaching platform of computer network technology course based on CLAROLINE [J]. Computer products and circulation,2017(7):25.

2. Qingjie Ma. Design and implementation of computer network teaching platform [J]. Information and computers, 2018(9):79-81.

3. Fang Li, Xianbin Yan. Adaptive research on "combination of teachers and students" in the view of constructivism [J]. Journal of langfang normal university (social science edition), 2012,(2): 115-117. 
4. Jianjuan Shao. Practical research on carrying out teaching mode reform in the construction of secondary vocational reform and development model school [J]. Scientific Chinese, 2014, (11): 187.

5. Silius,T.K..The Usefulness of Web-Based Learning Environments.[EB/OL].

http://matwww.ee.tut.fi/arvo/liitteet/usefulness of w eb.pdf, 2011-3-4/2011-4-6.
6. Kai Chen, Hanbing Wang, Huiyu Liu, et al. Design and implementation of computer network theory teaching support platform $[\mathrm{J}]$. Journal of electrical and electronic teaching,2017,39(3):105-109.

7. Kenan Yu. Analysis on the design and implementation of computer network teaching platform [J]. Computer fan,2017,(3):139-140.

8. Meina Xiao. Impact of cloud computing on teaching [J]. Information and computers, 2015,(21) : 58-59. 